\title{
RESEARCH ON THE CHALLENGES AND WAYS TO IMPROVE THE COMPREHENSIVE ABILITY OF CHINESE MUSIC EDUCATORS IN THE FUTURE
}

\author{
Cheng WL* and Kirliauskienè R \\ Education Academy, Vytautas Magnus University, Lithuania
}

\begin{abstract}
Music education, as an important form of music broadcasting, provides students with excellent aesthetic experience, cultivates their sentiment, develops their creative thinking, and also inherits the excellent cultural tradition, enriches the connotation of the world music culture, and promotes interpersonal communication and emotional communication. Music educators, as the main media of music communication, have a great responsibility. With China's rapid economic development, people's continuous pursuit of artistic quality, music educators is facing greater challenges. Facing this in the future, they urgent need to improve their comprehensive ability. This paper studied through literature and comparative study. Through the literature method, it consults the relevant literature at home and abroad, defines and explains the relevant core concepts, defines the content of the comprehensive ability of future music educators, and summarizes the current situation of music education in China. Through the comparative research method, the development course of Chinese music education is compared, and the experience and lessons are summarized. Finally, combined with the current actual situation of music education in primary and secondary schools in China, effective suggestions and opinions were put forward on the improvement of the comprehensive ability of music education educators in the future. This paper is divided into 3 parts. The first part reviews the contents of the comprehensive abilities of music educators. The second part analyzes the development process of Chinese music education and the current challenges. The third part puts forward the future music educators to improve the comprehensive ability.
\end{abstract}

Keywords: Future music educators, comprehensive ability, challenges, improvement

\section{Introduction}

\section{Research background}

There are currently 264081 primary school music teachers in China, of whom 4,282 have graduate degrees and 178518 have bachelor's degrees, according to the latest academic qualifications for full time teachers of primary credit courses released by the development and Planning Department of the Ministry of Education in June 2020, at present, there are 101876 music teachers in junior middle schools, including 2,633 graduate students, 85,529 undergraduate students, 13,576 junior college students and 138 senior middle school students According to the academic qualifications of the fulltime teachers of different courses in senior high schools, there are currently 33,603 music teachers in senior high schools in China, including 2,098 graduate students, 30,760 undergraduate students, 738 junior college students and 7 senior high school students. From the situation of music teachers in 
primary and middle schools in China, we can see that there is a large group of music educators in China nowadays. However, behind the huge group of music educators, there is an urgent need for music educators with high ability and quality. Especially with the rapid development of Internet and the coming of big data era, how to improve the comprehensive ability of music educators to meet the high requirements of the society has become a problem that the music education circle continues to study and discuss.

\section{Current status of research}

As one of the oldest, most universal and infectious art forms of mankind, music conveys a rich culture and history. Music Education, as an important broadcasting form of music, provides students with excellent aesthetic experience, cultivates their sentiments and develops their creative thinking. It also inherits outstanding cultural traditions and enriches the connotation of world music culture, promotes interpersonal and emotional communication. Music Education was introduced into China in the 1980s. Prior to this, the international music education has formed a more mature education system. Music educators and music education experts at home and abroad are very concerned about the development of music education. At the same time, the research on music education in China has been carried out steadily. In the Chinese authoritative literature search website China Knowledge Net, 9823 related articles and 742 master dissertations can be found by inputting "music education" as the key word, 9037 articles and 791 master dissertations by inputting "art education" as the key word The key words of "music teaching" can be inputted into 6119 related literatures and 393 master dissertations, while the key words of "music teacher" can be inputted into 4260 related literatures and 408 master dissertations. It can be seen that scholars attach great importance to music education. For the development of music education, we are actively thinking and offer suggestions.

\section{Music education}

Zhang, H. Y et al (2018) point out that: "the main purpose of music education is to enable the educated to acquire music knowledge and skills. Whether there are changes in behaviour, emotion, personality and spirit after the acquisition of music knowledge, skills and training has nothing to do with the educators, and this is not the aim of music education." (Zhang, Yue, \& Wang, 2018) According to Sun, Y (2010) "music education is an important part of liberal education, and dance education for children is an important part of music education for children, both of which fall under the category of kindergarten liberal education. In the art life of Modern Society, music and dance are independent arts. However, when children are engaged in music activities, music and body movements are often inseparable." (Sun, 2010)

Li, F (2014) proposed that: "music education is not only a matter within the scope of music. Through the edification and study of music, we should not only expand our musical horizons, enhance our sensibility, acquire musical knowledge and skills, it is important to realize the influence of music on people's life attitude. The ultimate goal of music education is to cultivate an optimistic attitude towards life and the habit of cooperation and coordination with the people around." ( $\mathrm{Li}, 2014)$

Different scholars give their own opinions on the function of music education. Liu, L (2014) believes that: "the end of music education is reflected in social function. As music students, they cannot always play at home or in the piano room, they need a lot of social practice to share the music with 
the audience. This is the last step of playing, the motive force of achieving the first five aspects, and the embodiment of aesthetic education achievement." (Liu, 2014)

The Ministry of Education of the People's Republic of China issued its latest revised Music Curriculum Standards in 2011 and published them in 2012. In the music curriculum standard, the music curriculum nature includes the humanity, the aesthetic, the practicality; The music curriculum basic idea divides into five parts: takes the music aesthetic as the core, takes the interest hobby as the motive force; Stress The music characteristic, pay attention to the subject synthesis; carry forward the National Music, understand the music culture diversity; face to all students, pay attention to individual development. (The Ministry of Education of the People's Republic of China, 2012)

Therefore, music education, like education, should have both broad and narrow meanings. Music Education in a broad sense refers to the conduct of imparting and edifying knowledge, skills, culture and moral quality through music appreciation, music learning and music creation Music education in a narrow sense mainly refers to music education in schools, including music courses in schools, music activities, music competitions and music training outside schools.

\section{Educators}

Education is an important way for human beings to go from barbarism to civilization, and to pass on and carry forward all kinds of excellent life experience. As the main carrier and important component of education communication, educators play a decisive role in education. There are different definitions of the concept of educator in the world. In China, some scholars have given their own understanding and definition of educators. Wang, D. J and Guo, W. N (2009) in the book Pedagogy point that: "educator mainly refers to school teachers and other education staff. The educator is a basic element of the educational activity." (Wang, and Guo, 2009) National Teacher Qualification Examination Research Centre defines the educators as: "educators have broad and narrow sense of division. An educator in a broad sense refers to all persons, including school teachers, who have an influence on the knowledge, skills, thoughts, morals, etc. of the educated, designers and authors of educational plans and textbooks and other persons involved in educational activities. Educators in a narrow sense refer to full-time educators such as school teachers and other educational staff. Educators play a leading role in educational activities." (National Teacher Qualification Examination Research Centre, 2015) Special Post Teacher Recruitment Examination Special Teaching Materials points that: educators are the people who engaged in educational activities. The broad sense of the educator refers to the person who plays an important role in the development of the mind and body, such as knowledge, skills and moral character. After school education came into being, educators mainly refer to teachers and other educational personnel in schools. The educator is not only the leader and executor of the educational activities, but also the main influence and guide of the students. Music educators are the main implementers of music culture communication and education. They not only take on the responsibility of teaching and educating people, but also take on the responsibility of training students' artistic ability and music appreciation ability. (Research Institute of Special Post Teacher Recruitment and examination in secondary education, 2016)

In a word, music educators also include a broad sense and a narrow sense. Music educators in a broad sense refer to all those who are engaged in music teaching, music culture communication, music habit formation, musical instrument skill teaching, etc. Music educators in a narrow sense refer to teachers 
engaged in music education and other music training institutions practitioners. Music educators discussed in this paper mainly refer to music educators in a narrow sense, that is, school music teachers.

\section{Comprehensive ability of educators}

Educators should have the corresponding professional knowledge and skills, but also should have the noble moral sentiment and quality. For the comprehensive ability of educators, scholars have many similar statements, such as comprehensive quality of educators, professional ability of educators, professional skills of educators, teacher specialization, and so on. No matter what kind of educators, they should have the corresponding comprehensive ability.

In 1982, American educator summarized the qualities of teachers through letters and visits to students: "friendly attitude; respect for every student; never give up on a person, until you do; have patience, broad interests; good appearance; flexibility; tolerance; method; public; good quality; personal concern; have a sense of humour." In 1990, Japanese educator surveyed junior and senior high school students, and found that: "the qualities of teachers were: Understanding Students; amiable and approachable; trustworthy; fair; clear; cheerful; sincere; earnest; punctual; lively; interesting in teaching; rich in knowledge; strong responsibility; serious; high level of teaching; democracy; meticulous; moral high moral; have faith; gentle."

As for the definition of teachers' comprehensive ability, some scholars in China hold the following view: Cai, M. C et al (2000) holds that, "the comprehensive quality of teachers should be: "professional quality, physical quality, psychological quality, professionalism, moral quality, innovative ability and so on." (Cai, et al. 2000) Chen, W. C (2018) pointed out that: "teachers' good comprehensive qualities are: the ability to understand the interaction between students and their parents; the ability to organize and manage students; the ability to guide students' physical and mental health; the teaching ability to guarantee the quality of teaching; the quality of education research; and the quality of educational intelligence ". (Chen, 2018) According to Sun, J, the comprehensive quality of high school teachers mainly refers to the sum total of the qualities that high school teachers display in their educational and teaching activities under the new curriculum conditions, which determine their educational and teaching effects and affect students' all-round development, these qualities are the organic unity of body and reason, society and morality, humanities and arts, science and innovation, education and teaching. (Sun, 2016)

In addition to the research conducted by scholars, a number of national legal and professional books also defined the comprehensive competence of teachers. The Teachers Law of the People's Republic of China stipulates that: "the professional quality of teachers includes professional knowledge and professional ability. The inherent characteristics of teachers' work require teachers to have cultural intelligence, social intelligence and emotional intelligence." (The Teachers Law of the People's Republic of China, 1994) The Graduate School of Teacher Recruitment and Examination for Secondary Education points out that teachers' comprehensive competence is not only their professional knowledge and theory, but also their other abilities that have a significant impact on education and teaching. It mainly includes teachers' language expression ability, class management ability, coordination ability, self-adjustment and self-reflection ability, etc. Chen, S. J (2015) et al. points out that "teaching ability is a special ability formed by teachers in the process of teacher role 
activities, and it is a synthesis of various abilities that affect teaching efficiency and effect." (Chen, 2015)

\section{Comprehensive ability of music educators}

The comprehensive ability of music teachers mainly includes the organic combination of teachers' professional skills, knowledge skills, educational ability, scientific research ability and communication ability. So for music educators, the comprehensive ability they should have should also include a variety of abilities. The research on the comprehensive ability of music teachers is very different at home and abroad. A Google search for music teacher abilities reveals that between 2010 and 2020 there were 196000 related articles and 51 related papers. However, only 1157 related articles can be found by searching "teachers' comprehensive ability", and only 61 articles can be found by entering the keyword "music teachers' comprehensive ability".

Hou, X. L (2019) believes that: "the comprehensive quality of music teachers, in fact, it includes many aspects, such as the ability to sing and play, the ability of teaching reform, the ability of language expression, cultural quality, and cultural accomplishment and so on. The so-called enhancement music teacher's comprehensive quality, actually also is to music teacher compound talented person's raise, in short needs the music teacher one specialized multi-ability." (Hou, 2016) Wang, Y. J (2019) proposed that: "music teachers should have professional abilities, including singing ability, piano ability, dance ability, conducting ability and composition ability; teaching ability, including innovation ability, language expression ability, organization and management ability, information technology ability, research capacity." (Wang, 2019)

In a word, the author thinks that the comprehensive ability of music educators in the future should include professional ability, educational ability and scientific research ability. The professional ability includes the basic music accomplishment, the music specialized knowledge foundation, the music specialized skill; the education ability includes the music teaching ability, the communication ability, the training instruction ability, the Organization Management Ability; The scientific research ability includes the information technology ability, the question research ability, promotes the study ability and so on.

Looking back on the history of music education in China, there are many challenges along the way. It is the efforts of countless determined music educators that have brought about the vigorous development of music education in China. Thus, in different stages, music educators have to face all kinds of opportunities, will encounter all kinds of difficulties. Music educators need to constantly improve their comprehensive ability and constantly improve themselves to face the challenges.

\section{Research questions and objectives}

\section{Research Questions}

1. What is the status quo of music education in China? What's the problem?

2. What are the challenges facing Chinese music educators?

3. How to improve the comprehensive ability of future music educators? 


\section{Research objectives}

By consulting relevant literature at home and abroad, this paper defines and explains the core concepts, comprehensively analyses the current situation and problems of music education in China, and finally combines the actual situation of music education in primary and middle schools in China, this paper puts forward some effective suggestions and opinions on improving the comprehensive ability of music educators in the future, so as to contribute to the development of music education in China.

1. To analyze the problems and challenges faced in the comprehensive ability and work of future music educators in the scientific literature

2. To analyze the key problems facing future music educators

3. To find ways to improve the comprehensive ability of music educators

\section{Research Methodology}

1. Literature method: Through literature method, consult relevant literature at home and abroad, define and explain relevant core concepts, define the comprehensive ability of future music educators, and summarize the current situation of Chinese music education

2. Comparative study method: Through the comparative research method, compare the development process of Chinese music education, and summarize the experience and lessons

\section{Current situation and challenges of Music Education in China}

\section{Current situation of music education in China}

\section{The State attaches importance to music education and constantly improves the policy system}

At present, the national level of music education is very important, as the key content of education to layout and promote. In 2015, the State Council General Office issued the Opinions on Comprehensively Strengthening and Improving School Aesthetic Education, the first school aesthetic education document issued by the State Council since the founding of the People's Republic of China, at present and in the future a period to promote the school aesthetic education reform and development to make a comprehensive deployment. In 2015, the Ministry of Education issued the Measures for the Assessment of the Artistic Quality of Primary and Secondary School Students, the Measures for the Self-assessment of the Work of Art Education in Primary and Secondary Schools and the Measures for the Annual Report on the Development of Art Education in Primary and Secondary Schools, to fill the gaps in the school aesthetic education assessment system, to evaluate the quality of school aesthetic education in an all-round and three-dimensional way. In 2017, the Ministry of Education issued the Management Measures for Part-time Teachers of Physical Education and Aesthetic Education in Schools to solve the current shortage of physical education and aesthetic education teachers. In 2018, the day after General Secretary Xi, J. P's reply to a letter from a senior professor at the China Central Academy of Fine Arts was announced, the party group of the Ministry of Education immediately issued the notice on learning and implementing the spirit of General 
Secretary Xi Jinping's Important Reply to a Senior Professor at the China Central Academy of Fine Arts, make arrangements for the education system to learn and implement the spirit of the general secretary's important reply letter. In April 2019, the Ministry of Education just issued the Opinions on Strengthening the Work of Aesthetic Education in Colleges and Universities in the New Era, putting forward clear requirements for the reform and development of aesthetic education in colleges and universities in the new era, it is an important guide to guide and promote the reform and development of aesthetic education in colleges and universities in the new era.

In 2012, Chinese Vice Minister of Education, Hao, P delivered a speech at the 2012 National Education Work Conference, emphasizing the implementation of the National Plan for the Development of Art Education in Schools (2011 -- 2020) . She emphasized that: "First, efforts should be made to ensure that teachers of sound, body and beauty in compulsory education schools throughout the country are well matched and that equipment is up to standard. Revise the catalogue of Music and art teaching equipment for compulsory education schools. Second, we must vigorously strengthen the school art teaching. Study and formulate the syllabus of art course in secondary vocational schools. Promote the teaching reform of music and fine arts in colleges and universities. Continue to organize and develop high art activities on campus and organize national university, primary and secondary school students' performing arts activities. Third, we must strengthen the training of art teachers. Continue to organize the "National Training Program (2012) for primary and Secondary School Art Backbone Teacher Training Program", hold national primary and secondary school art backbone teachers and provincial teaching and research staff training classes, organize the "send training to local" art teachers training." (Luo, 2017)

On October 11th, 2012, the National Children's Song and Dance Drama Music Education pilot work spot meeting was held in Shanghai. It emphasized that continuing to promote the national children's song and Dance Drama Music Education pilot work, through popularizing children's song and dance drama, to give full play to the art education's imperceptible influence function, to plant the spirit gene of truth, goodness and beauty in the students' hearts, and to enrich the emotional experience of the students in the process of participating in the study, composition, rehearsal and performance of children's song and dance dramas, improve the ability to use language, music and body movements to express meaning, stimulate imagination and creativity, enhance self-confidence and sense of achievement, cultivate collectivism spirit, teamwork ability, build a healthy and upward personality. (Liu, 2015)

In April 2019, the Ministry of Education of the People's Republic of China released the Ministry of Education on the Practical Strengthening of Institutions of Higher Learning in the New Era, offering suggestions for the future work of aesthetic education. Demanding that by 2022, breakthrough progress be made in aesthetic education in colleges and universities, significant results be achieved in the reform of aesthetic education and teaching, the construction of teaching staff and facilities be strengthened, and the promotion mechanism and evaluation system be improved day by day, the aesthetic and humanistic qualities of college students have been greatly improved. By 2035, we will have a diversified, high quality, socialism with Chinese characteristics, Modern College and university aesthetic education system. 


\section{Significant achievements in music education}

Under the promotion of the National Policy, national music education has been steadily developed. By 2019, according to the Ministry of Education, 93.5 percent of provinces (autonomous regions and municipalities) will have met the state's 9 percent quota for music and fine arts courses at the compulsory education level, 92.1 per cent of the country's schools are able to offer a six-credit compulsory course in the arts category; 75.7 per cent of the country's secondary vocational education schools have included the arts in the compulsory public basic course and have guaranteed 72 school hours; Eighty-four-point-six percent of the country's colleges and universities offer public art courses to all students. Aesthetic education curriculum resources are increasingly rich. Local and local schools are actively developing and utilizing local ethnic and folk aesthetic education resources, enriching the content of aesthetic education courses, deepening the reform of aesthetic education teaching, and constructing an aesthetic education curriculum system with aesthetic and humanistic qualities as its core, in primary and secondary schools to add dance, drama, drama, Film and Television Courses. The number of aesthetic education beneficiaries has been expanding. The survey showed that nearly 87 per cent of students received arts education in primary and secondary schools, and 65 per cent participated in arts clubs or interest groups to learn and master arts skills.

The steady development of music education within the school, Music Education and cultural heritage of the deepening of integration, all kinds of off-campus music education activities are in full swing. Nationwide, 80 percent of students from universities, middle schools and primary schools and 90 percent of institutions of higher learning participated in art exhibitions. The Rural Art Education Pilot Counties Project has established 184 pilot counties in 31 provinces (autonomous regions and municipalities) nationwide. The program has built 1,484 schools and 55 bases in primary and secondary schools and universities across the country. Every two years, we will hold an exhibition of basic skills for undergraduate students majoring in music and fine arts education in ordinary colleges and universities across the country, and create new models for training talents, to build a contingent of highly qualified, professional and innovative music and art teachers to meet the needs of the reform and development of the basic education. Sports, Art " $2+1$ " Project faces for all primary and secondary students and promotes each student to master one or two artistic expertise.

\section{The ranks of music teachers continue to grow}

The number of music teachers in compulsory education has increased from 434,100 in 2008 to 717,000 in 2018; average annual growth rate of aesthetic education teachers has reached $8.7 \%$. The distribution of aesthetic education equipment and facilities has been greatly improved. From 2008 to 2018, the rate of meeting the standards for art equipment in primary schools nationwide rose from 45.6 percent to 93.8 percent, and in junior middle schools from 59.8 percent to 95.5 percent, an increase of about 42 percentage points in 10 years. There are about 249 institutions of higher learning nationwide offering music-related majors, of which 45 are pilot schools for undergraduate courses in musicology (teacher training). China's music colleges and universities will send more than 200 million music graduates to the country every year. China's music higher normal colleges and universities will send more than 2.5 million music education talents to society every year, expanding the strength of our music education teachers in primary and secondary schools. 


\section{Problems in the development of music education in China}

Although the development of music education in China has made steady progress, there are still some problems and development problems. First, there is a big gap for music teachers. China is a vast country with uneven distribution of teaching resources. Some remote areas and poor mountainous areas lack of educational resources and poor teaching conditions. Currently, there are 136 counties in China that have not been approved by the state and are located in nine provinces (regions) of Inner Mongolia, Henan, Hunan, Guangxi, Sichuan, Tibet, Gansu, Qinghai and Xinjiang. Of these, 44 are triprefectures and 24 have yet to be lifted out of poverty. In 2019, the National Education Supervision and Inspection Group conducted a survey on the balanced development of compulsory education in many provinces and found that the structure of teachers in many places is unreasonable, and the shortage of music teachers is large. Secondly, the concept of music education is relatively backward. At present, there are still some "professional art" in music education, which needs to spend a lot of money. To some extent, it affects the popularization of music education. Compared with the diversified development of international music, most people in China, even music educators, still have the wrong idea. Everything is based on the European music culture as the standard to measure the advancement and backwardness of music, belittle the education of Chinese traditional music.

\section{The way to improve the comprehensive ability of music educators in the future}

Music educators face many challenges and puzzles, as well as many opportunities. No matter from the national, social or individual, the increasing spiritual and cultural demand has provided many opportunities and approaches for the improvement of music educators' comprehensive ability.

\section{Fully strengthen theoretical knowledge and improve ideological quality}

Zhang, Y (2007) pointed out that: "China's basic music education is an integral part of the liberal education, but for a long time because music is a non-entrance examination subjects, it has not received real attention from society and schools, so that the primary and secondary school music education deviates from the track of quality education. When people think that music can indoctrinate people, they use moral education instead of music aesthetic; when people think that music can develop intelligence, they use intellectual education instead of music experience. The music teacher's work also did not receive the school to take the art festival, each kind of competition as the music teacher's work. Some music teachers themselves neglect music teaching, do not take the classroom teaching as the main topic research teaching method, the way is simple, immerses in the specialized music training, takes the specialized music knowledge as the classroom support point. The on-the-job training of music teachers has not been carried out properly, and there is sometimes a phenomenon of derailment and disconnection from the actual work. Some music teachers also lack the spirit of autonomous learning, and have inert thoughts, etc. all these hinder the professional development of music teachers." (Zhang, 2007)

The teacher's emotion affects the classroom teaching effect, affects the teacher-student relationship development, and affects the student's emotion development. Music educator is the first identity of the educator; the primary responsibility is to teach people. In the process of music teaching, music educators should improve and enrich their theoretical knowledge, including the history of music development, the national spirit contained in music, the relationship between music and culture, etc. , 
with the help of music teaching, students should have a correct outlook on the world, life and values, and a correct musical thought. In addition, music educators should have compassion and carry forward the spirit of music. Strengthen communication with students, go into students' thoughts, instill correct consciousness in students from the ideological level.

Han, Y (2015) believes that: "primary school music teachers should have the spiritual quality of loving music education. As a music teacher must first love music, music has a special perception, to have a full mood, enjoy having a strong interest. Only teachers themselves are moved, can guide students to be infected, and then achieve the teaching purposes. Second, we should love the cause of music education." (Han, 2015)

\section{Skillfully using information technology to improve teaching ability}

At present, the rapid development of domestic Internet technology, a variety of information technology emerge one after another, emerging teaching mode also began to get time in various stages of teaching, such as micro-class, MOOC, VR real technology and so on. Wang, Y. J (2019) thinks that: "in the same way in music education, with the deepening of music education reform, the traditional music teaching mode has not adapted to the needs of modern teaching. Because information technology is an auxiliary means of teaching for education, it is convenient and efficient. If it can be properly used in music teaching, it will not only enrich the content of music learning, but also stimulate students' interest in learning. Students can also get more music learning resources on their own, which improves the teaching efficiency." (Wang, 2019)

Music teaching mode is not immutable, and simply listening cannot meet the needs of students. Using music editing software, mobile music editing APP, and so on, students can try to adapt. The teaching model of turning over classroom and student-based education is also suitable for music teaching. Before the class, let the students use the Internet, find the background knowledge of music, understand the musician information, read the music score and so on After-school music can provide a variety of learning resources to expand students' music knowledge, enrich students' music life. During the end of 2019, many music teachers tried to teach on-line to teach students the use of musical instruments, music theory knowledge, which fully achieved interactive teaching.

\section{Consult with an open mind, think seriously and improve management ability}

Music educators may be dealing with one person, or with a collective class. Whether it is to face the individual or the collective music educators need to have a certain organizational and management capacity. Especially in the Organization of extra-curricular music activities, out of the constraints of the classroom context, students tend to relax awareness. Therefore, it is particularly important to be a wise and discoverable music educator. The ability of organization and management of teachers is a kind of complex comprehensive ability. In addition to the performance of the Organization of teaching work, it is very important to the performance of a good class collective organization. The teacher must be good at planning and arrangement, must have the thorough arrangement and the inspection, and forms the good order and the system, creates the good environment, causes the student earnestly to realize the teacher's instruction. An important aspect of teachers' organizing ability is to make full use of the students' collective strength to push the work and to avoid "single-handed combat". It has been proved that it is often better to solve some difficult problems through group work and peer-to-peer help than by teachers themselves. Music teachers should be good at observing each 
student, find out their talent in music, and understand their psychological changes, according to the actual situation of teaching method adjustment. As a result of the music teacher as head teacher the opportunity is quite few, lacks the experience in the class management. When teaching large classes in the classroom, we should communicate with other experienced teachers and seek methods of class management and activity organization. The music teacher often has the affinity, may through the music take the medium to communicate with the student, relaxes the student mood. Music educators should make full use of their disciplinary advantages to improve their self-management ability.

\section{Actively participate in practical exchanges to improve scientific research ability}

If music educators want to improve themselves, they cannot be self-complacent, and they need to make a reasonable career planning. Based on the fact that career planning plays an important role in the management of career development and is the guarantee of effective implementation of career development, good career planning can make teachers' teaching objectives more clear, therefore, music teachers are required to fully consider their own conditions while taking into account the problems existing in the actual teaching and scientific research process, the facilities and systems provided by schools, and according to their own professional development situation, timely development of their own career planning. Music educators should actively participate in music exchange activities; learn from other people's excellent experience, to understand the latest international trends in music development, to find the most prominent problems of music education. In the process of teaching, educators should turn "difficulties" into "opportunities", turn "problems" into "topics", and actively participate in scientific research activities. At present, education departments at all levels pay more attention to teachers' scientific research ability, and have higher requirements for teaching and scientific research. In addition, nowadays, with the development of the Internet, all kinds of learning resources and research literature can be found anywhere and anytime. Music educators should grasp the opportunity, strengthen self-request and improve scientific research ability.

\section{Conclusion}

Music educators are similar to other educators in that they all need to impart knowledge, skills and sentiments, but they are different from traditional educators, the knowledge and skills they pass on are more displayed in the aspect of art appreciation, and the ideological education to the learners is imperceptible. And, because needs to carry on the teaching by the music, the music educator's teaching way has been certain limit. Therefore, how to improve the comprehensive ability of music educators is also a problem worthy of study and in-depth discussion.

At present, Chinese music educators are faced with many challenges, and there are still some deficiencies in Chinese music education, such as the uneven proportion of teachers' knowledge structure, the "partial subject" of theoretical courses, and the weak ability of teaching and scientific research. All of these urge future music educators to seek ways to improve their comprehensive ability. First of all, music educators should strengthen theoretical knowledge and pay attention to the change of self-concept. Second, they also need to adapt to the requirements of the Times, make full use of information technology. Third, they also need to be bold and ask questions to improve their self-management skills. Finally, teachers also need to actively participate in exchange learning activities. 
In this paper, from the perspective of music educators and students in the current environment of music educators' comprehensive ability to enhance the experience and problems encountered, and combined with the current research experience of many scholars, from the aspects of national policy, social environment, technical support and teachers' self-demand, this paper puts forward some suggestions to improve the comprehensive ability of music educators in the future. This paper sums up some methods and ways to improve the comprehensive ability of the future music educators and to develop the future music education. But in the proposed, but also lack of self-practice after the summary of experience, opinions and recommendations are not comprehensive enough. All these will be improved and perfected in the future research.

\section{References}

Cai, C., Huang, Q. Y., Fan, Y. M., \& Liao, W. G. (2009). Improving the comprehensive quality of teachers to build a first-class teacher team. Xian, China: Northwest Medical Education.

China Public Education Teacher Recruitment Examination Research Institute. (2016). China public education edition $\bullet 2016$ teacher recruitment examination special textbook: middle school of basic knowledge of education theory. Beijing, China: World Book Publishing Company.

Chen, W. C. (2018). Research on improving the comprehensive quality of rural teachers in Wangfu Town Maoming City. Nanchang, China: Nanchang University.

Editorial Committee of Special Textbook for Guangxi Primary and Secondary School Teachers' Open Recruitment Examination. (2015). (2015 latest edition) Special textbook for Guangxi primary and secondary school teachers' open recruitment examination: basic knowledge of educational psychology and moral education. Beijing, China: Hongqi Press.

Editorial Board of Special Teaching Material for Special Post Teacher Recruitment Examination. (2016). Special teaching material for special post teacher recruitment examination: one book for special post teacher recruitment examination. Beijing, China: World Book Publishing Company.

Han, Y. (2015). How to improve the professional quality of primary school music teachers. Beijing, China: Quality Education.

Hou, X. L. (2016). Comprehensive ability training of music teachers in higher vocational colleges. Harbin, China: Northern Music, (17):129.

Li, F. (2016). Kindergarten education management guide. Shanghai: East China Normal University Press.

Liu, Y. (2014). Elementary discussion on diversified music enlightenment education. Beijing: Social Sciences Academic Press.

Liu, Y. (2005). Exploring the professional development of music teachers in the implementation of new curriculum. Beijing, China: Capital Normal University.

Luo, R. Q. (2017). Career development of music teachers in local colleges and universities -- a case study of Hunan Province. Changsha, China: Hunan Agricultural University.

Ministry of Education, PRC. (2012). Music Curriculum Standards for Compulsory Education. Beijing, China: Beijing Normal University Press.

Ministry of Education, PRC. (1993). Pedagogic law of the People's Republic of China. Beijing, China: The Ministry of Education of the People's Republic of China.

Research Center of National Teacher Qualification Examination. (2015). The General Textbook of National Teacher Qualification Examination -- Educational Teaching Knowledge and Ability (primary school). Beijing, China: People's Posts and Telecommunications Press Co., LTD. 
Sun, J. (2016). Research on the comprehensive quality of high school teachers. Xian, China: Shanxi Normal University.

Sun, Y. (2010). Good habits make a child's life. China: China Textile Publishing House.

Wang, D. J, \& Guo Wenan. (2009). Education. Beijing, China: People's Education Press.

Wang, Y. J. (2019). Analysis and research on the professional comprehensive ability of music teachers in primary and secondary schools. Beijing, China: Chinese Music Education, (2):68-69.

Zhang, H. Y., Yue, X. D. \& Wang, H. W. (2018). Film therapy: a film therapy class with 10 psychologists. China: Zhigong Publishing House.

Zhang, Y. (2007). Comparison and research on professional development of music teachers in Chinese and foreign primary and secondary schools. Dalian, China: Liaoning Normal University. 